Int. J. Electrochem. Sci., 14 (2019) $2780-2803$

International Journal of

ELECTROCHEMICAL

SCIENCE

WWW.electrochemsci.org

\title{
The Inhibition Effect of Some Organic Compounds on Corrosion of Brass and Carbon Steel in Aggressive Medium
}

\author{
Florina Branzoi* ${ }^{*}$ and Adriana Băran \\ Institute of Physical Chemistry, 202 Splaiul Independenţei, Bucharest, Romania, \\ E-mail fbrinzoi@ chimfiz.icf.ro
}

doi: $10.20964 / 2019.03 .55$

Received: 19 October 2018 / Accepted: 18 December 2018 / Published: 7 February 2019

The surfactants Triton X100 and Triton A20 were studied as corrosion inhibitors for brass and carbon steel type OL37 in sulfuric acid medium using potentiodynamic polarization measurements, electrochemical impedance spectroscopy (EIS), FT-IR spectroscopy and metallurgical microscopy methods. We suppose that, these surfactants inhibit corrosion of metal electrodes by a protective mechanism can be owed to either the adsorption of inhibitor molecules forming a protective film or obtaining a insoluble compound and repairing the porous oxide layers. Experimental data showed that these surfactants achieved a significant inhibiting effect on brass and carbon steel corrosion and act that a mixed inhibitor. The adsorption of the non-ionic surfactants on the electrodes surface obeys to the Langmuir isotherm model. The temperature influence on the corrosion behaviour of the metal electrode in $0.5 \mathrm{M} \mathrm{H}_{2} \mathrm{SO}_{4}$ with and without the inhibitor at $100 \mathrm{ppm}$ and $800 \mathrm{ppm}$ was analyzed in the temperature domain from 293 to $313 \mathrm{~K}$. The negative value of thermodynamic parameter like Gibbs free energy of adsorption shows the spontaneity of adsorption process. The experimental results indicate that these inhibitors established its corrosion protection ability. The best effectiveness is achieved at the inhibitor concentration of 100ppm for the system Triton X100/OL 37 and 800ppm for Triton A20/brass.

Keywords: organic inhibitor, brass, carbon steel, electrochemical methods, FT-IR spectroscopy

\section{$\underline{\text { FULL TEXT }}$}

(C) 2019 The Authors. Published by ESG (www.electrochemsci.org). This article is an open access article distributed under the terms and conditions of the Creative Commons Attribution license (http://creativecommons.org/licenses/by/4.0/). 